\title{
EDUCAÇÃO E OUTROS MITOS: CENAS DE SÃO PAULO NO IV CENTENÁRIO
}

\author{
Fernanda Franchini* \\ lattes.cnpq.br/1335653581529882
}

\begin{abstract}
Resumo: Este trabalho tem por objetivo abordar as imagens das comemorações do IV Centenário da cidade de São Paulo difundidas em edição de um cinejornal, o Bandeirante da Tela. Esses eventos foram realizados no início de julho de 1954 e promovidos pela Associação das Emissoras. A análise desse documento fílmico coloca em destaque uma narrativa construída sobre a história da cidade na qual símbolos e temas educacionais formavam um de seus elementos. Em termos teóricometodológicos levaremos em conta a historicidade e materialidade do documento, além dos elementos de composição da linguagem fílmica.
\end{abstract}

Palavras-chave: Cinejornal; Cidade; Educação.

\section{EDUCATION AND OTHER MYTHS: SCENES OF SÃO PAULO IN THE IV CENTENNIAL}

\begin{abstract}
This work has the objective to approach the images of the celebrations of the IV Centenary of São Paulo City shown in edition of a newsreel, the Bandeirante da Tela. These events were held in early July 1954 and were promoted by the Association of Broadcasters. The analysis of this document highlights a narrative built on the history of the city in which symbols and educational themes formed one of its elements. In theoretical-methodological terms we will take into account the historicity and materiality of the document, as well as the composition elements of the film language.
\end{abstract}

Keywords: Newsreel; Education; City.

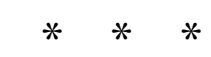

\footnotetext{
* Doutoranda em Educação pela Universidade de São Paulo, USP (Brasil). Contato: fernandafranchinig@gmail.com.
} 


\section{Introdução}

Uma série de eventos e projetos políticos foram delineados desde o final da década de 1940 para o IV Centenário da fundação da cidade de São Paulo. Muitas expectativas foram lançadas pelas elites dirigentes paulistas para esse ano de celebração da cidade, com intenção de demonstrar a aceleração da urbanização, de adotar símbolos que a elevassem ao status de representante da história nacional e de reforçar os seus ares de metrópole.

No que diz respeito à educação, um dos projetos que já estava em voga era o estabelecimento de um Convênio Escolar (entre Estado e Município, assinado em 1949 para ser concluído em 1954) que visava à ampliação da rede de escolas da Capital do Estado de São Paulo até o ano comemorativo com o propósito de diminuir os déficits de vagas para o elevado número de crianças em idade escolar sem acesso ao ensino ${ }^{1}$. Decorrente do processo de industrialização, a cidade passava por um intenso crescimento populacional oriundo dos fluxos migratórios, e as pressões populares por escolas acendiam ao ponto de tornarem-se tema nos debates políticos e pauta nos meios de comunicação (SPOSITO, 1992; ABREU, 2007).

Em paralelo ao projeto de construção das escolas, uma Comissão começou a ser instalada em 1948 para organizar os festejos dos 400 anos de São Paulo². Os preparativos envolviam diversos âmbitos culturais: dança, música, teatro, cinema, artes plásticas e esportes. Havia desde o início a preocupação de incluir as principais atividades que movimentavam a cidade e representavam o crescimento urbano, a dinamização da economia e as instâncias culturais. A Comissão passou por mudanças de gestão já na iminência das comemorações, o presidente executivo Fran-

\footnotetext{
${ }^{1}$ Este foi o $2^{\mathrm{O}}$ Convênio Escolar entre o Estado e Município de São Paulo, assinado pelo governador Adhemar Pereira de Barros (PSP) e o prefeito Asdrúbal da Cunha (PSP). Em 1943, um primeiro Convênio foi assinado pelo interventor Fernando da Costa e prefeito Francisco Prestes Maia, durante o período ditatorial do Estado Novo. 2 Iniciada pelo prefeito Paulo Lauro (PSP). Naquele ano, o governador era Adhemar Pereira de Barros (PSP).
} 
cisco Matarazzo Sobrinho renunciou logo após a entrada de Jânio Quadros na Prefeitura. Passada a comemoração em janeiro, Guilherme de Almeida assumiu o cargo para continuar a organização dos eventos ao longo do ano (LOFEGO, 2004, p. 56).

Os festejos do aniversário da cidade em 25 de janeiro (iniciados dois dias antes, incluindo 23 e 24 de janeiro) contaram com hasteamento de bandeiras, desfiles e concertos de bandas e fanfarras. Nesses dias, também ocorreram a inauguração da Catedral da Sé, o lançamento da pedra fundamental da nova sede da Universidade de São Paulo (Cidade Universitária), o encerramento do IV Congresso Brasileiro de Arquitetos e as premiações da Exposição Internacional de Arquitetura e da II Bienal de Artes.

A agenda do ano foi também composta pelo I Festival Internacional de Cinema nos dias 12 a 26 de fevereiro. O evento gerou uma ampla comoção na cidade, com a vinda de delegações de diretores, atores, atrizes, produtores e jornalistas de vários países (Estados Unidos, Alemanha, Itália, França, Argentina, Japão e outros).

Além disso, foi inaugurado o Parque do Ibirapuera no mês de agosto. Juntamente com a inauguração, iniciou-se a Exposição Histórica de São Paulo no Pavilhão de Exposições. No ano anterior, já tinha sido entregue o Monumento às Bandeiras em frente ao parque, também inserido no conjunto das obras para as comemorações.

Entre os eventos que ocorreram ao longo de 1954 pela cidade, coloco em destaque neste trabalho a análise dos dias 9, 10 e 11 de julho organizados pela Associação das Emissoras do Estado de São Paulo. Um resumo desses momentos de celebração do aniversário da cidade juntamente com a rememoração da chamada "Revolução de 1932" foi apresentado em uma edição especial do cinejornal Bandeirante da Tela que é a fonte histórica principal das análises deste artigo. 


\section{A cultura em meados do século $\mathrm{XX}$ : e o que é um cinejornal?}

Este texto pode se inserir no plano de um estudo mais amplo sobre as representações de cidade e de educação divulgadas a partir dos meios de comunicação, com destaque para o cinema. Compreende-se como marco temporal os 10 anos que se seguem depois do fim Segunda Guerra Mundial, no que se inclui a abertura democrática no Brasil (final do Estado Novo). Trata-se de um período de reordenação da política nacional e mundial, o que implicou na utilização da mídia como um recurso de propaganda para a construção das imagens dos países na nova reordenação mundial e para a difusão de uma política econômica desenvolvimentista articulada por políticos e industriais.

São Paulo, a essa altura, já possuía o maior índice de urbanização do país. Vivia a implantação de outros ramos de produção industrial além do têxtil e vestuário, como metalurgia, elétrica e automobilística. $\mathrm{O}$ espaço urbano ocupado também pela burocracia e comércio se consolidava como um lugar de grande atração populacional. Crescia o número de automóveis e ampliava a abertura de ruas e avenidas. Concomitante a isso, foi viabilizada uma série de investimentos no âmbito da cultura:

Se em 1940 a cidade contava com 16 bibliotecas públicas, 12 emissoras de rádio, 42 cinemas e 4 teatros, já em 1954 registrava-se a existência de 114 bibliotecas, 17 emissoras de rádio, 166 cinemas e 15 teatros e "mesmo assim a população acaba se comprimindo na porta (dos cinemas), em filas quilométricas, obrigando a sessões que começam às 10 horas da manhã e terminam às 2 da madrugada”. (LINGUANOTTO, 1954 apud MATOS, 2001).

Para pensar sobre processos de urbanização e o que pode ser entendido por cultura, podemos recorrer às diferentes apropriações desse termo que se deram ao longo do tempo, tomando como referência as análises de Raymond Williams em seus estudos sobre política, literatura e mídia. A associação "natural" entre cidade e cultura que fazemos no mundo contemporâneo é na verdade o resultado de complexos processos 
sociais que assinalam uma sequência de desvios semânticos. Da ideia de "cultivo" (cultivar a terra), para um substantivo abstrato associado às questões do espírito, diferenciando-se de "civilização", chegando até a incidência dos produtos culturais e a consolidação de uma noção de cultura "de massa" no século XX que se estabeleceu nos espaços urbanos (WILLIAMS, 2007).

Uma cidade global, moderna ou com status de metrópole deve conter instituições de cultura e a circulação de produtos culturais. A produção de cultura serve para "conformar" os indivíduos nesses espaços urbanos, fundamentalmente coletivos. Imprensa, rádio, cinema (e posteriormente, a televisão) podem ser analisados como produtos que ressignificam e alteram as consciências sobre os aspectos práticos da sociedade. As escolas são espaços de formação por excelência, assim como o cinema que em princípio era visto como meio de diversão popular, passa também a servir para educar os indivíduos para a vida na cidade.

Ora, se para Williams cultura é um modo geral de vida, fazer sua análise representa descrever as inter-relações entre as práticas de significações que articulam e organizam a vida social. Isto requer, portanto, uma interpretação capaz de dar conta das instituições que conformam o sistema de significações ao qual a cultura, especificamente em estudo, se faz realizar. A vida social se processa segundo um sistema organizado, em que não é possível separar, desmembrar, isolar o produto cultural. Esse sistema é significado em meio a todo um sistema também significado, o que representa, no final da linha, admitir que cultura é um sistema de significação. (EAGLETON, 2005, p. 129).

Tanto o cinema como a construção de estabelecimentos de ensino constituem-se em iniciativas para o desenvolvimento de uma cidade cosmopolita, constantemente requeridas pela população e citadas nos discursos políticos. De um lado, ocorreram esforços para o aumento do número de vagas nos parques infantis, cursos pré-primários, primários e secundários, além da construção de uma série de instituições privadas com apoio estatal para o ensino profissional (como o SESI, o SENAC e o 
SENAI)3 (SPOSITO, 2001). Em paralelo, nos anos 1940 e 1950, ocorreu a expansão dos números de cinema tanto no centro da cidade quanto pelos bairros (SANTORO, 2004). Muitos dos espectadores eram também estudantes das diversas instituições de ensino espalhadas pela cidade.

Os filmes estrangeiros, em especial hollywoodianos, mas também italianos, franceses e alemães dominavam o mercado de ficção que era o mais popular. A circulação de filmes de ficção produzidos no Brasil era extremamente reduzida, e isso se explicava pelas dificuldades na compra de equipamentos para a produção, mas também, pela propaganda massiva e pelas formas de distribuição das grandes corporações industriais estado-unidenses 4.

Os cinejornais eram exibidos antes dos filmes de longa-metragem nas sessões das salas de cinema. Denominados também pelo termo jornais da tela ou em outros idiomas como newsreels em inglês, cinegiornali, em italiano, noticieros, em espanhol, actualitè, em francês e wochenshau, em alemão. No Brasil, esses documentários apresentados em formato de notícias representavam a maior produção fílmica nacional do século XX55. Esses jornais cinematográficos eram realizados e distribuídos por particulares ou pelos governos, principalmente em decorrência dos recursos provindos da própria obrigatoriedade e das cotas de exibição ${ }^{6}$.

A produção dos cinejornais no Brasil elucida de certa forma os contextos da transição de sentidos dados à cultura. A criação do Departa-

\footnotetext{
3 As siglas significam: Serviço Social da Indústria (SESI), Serviço Nacional de Aprendizagem Comercial (SENAC) e Serviço Nacional de Aprendizagem Industrial (SENAI).

4 Como a Fox, Warner Bros e Paramount.

5 Esse tipo de filme foi produzido até os anos 1980, quando foram progressivamente deixando de circularem nos cinemas brasileiros.

6 Desde 1934, o decreto 21.240/32, além de ter regulamentado o Serviço de Censura no Brasil definiu a obrigatoriedade dos complementos nacionais (filmes educativos e cinejornais) nas sessões das salas de cinema. Em 1951, o decreto 30.179/51, instituía a obrigação de um filme brasileiro para oito filmes estrangeiros e os importadores deveriam adquirir anualmente produções brasileiras de complementos nacionais na proporção de 50\% da metragem dos filmes estrangeiros adquiridos. Em 1953, depois de um acordo realizado com os Estados Unidos em virtude de um empréstimo financeiro ao governo brasileiro, foi permitida a livre entrada de cinejornais daquele país (TOMAIM, 2011).
} 
mento de Imprensa e Propaganda (1939) e do Instituto Nacional do Cinema Educativo (1936) estava atrelada às políticas nacionalistas próprias do período ditatorial7. Nos anos seguintes, os cinejornais passaram a enfocar uma narrativa política tratando então, da expansão do capital industrial e comercial ${ }^{8}$. É por isso, por exemplo, que para Raymond Williams os estudos sobre a sociedade não podem ficar apartados dessas questões, a cultura é parte constitutiva dos processos históricos políticos e econômicos.

Apesar de estudos um pouco mais frequentes entre os pesquisadores do cinema e da história política e social ${ }^{9}$ que tomam como objeto os cinejornais, ainda é evidente o ineditismo nos campos das pesquisas sobre o urbano e também são poucos os trabalhos na História da Educação $0^{10}$. Contudo, trata-se de uma fonte que pode contribuir para a elaboração de trabalhos sobre as cidades na medida em que traz elementos para o estudo das representações e dos usos das imagens na formação de estereótipos sobre os vários grupos sociais. No que incide à educação, é possível escrutinar as apropriações realizadas no contexto de preparação desses filmes dos debates sobre os processos de escolarização, os ideais sobre o ensino direcionado às classes trabalhadoras e às elites, as diferenças na formação de homens e mulheres e os cuidados e atendimentos na infância ${ }^{11}$.

\footnotetext{
7 Responsáveis pela viabilização de filmes documentais (cinejornais e filmes educativos) no Brasil. Tinham características análogas aos órgãos de propaganda na Itália e na Alemanha.

8 Mais alinhados às pretensões dos Estados Unidos para a expansão do capital e das zonas de influência econômica.

9 Como os trabalhos de Souza (2003) e Medeiros (2008); Simis (1996), Santos (2004), Tomaim (2006) e Archangelo (2015).

${ }^{10}$ Nesta área somente foi encontrada a dissertação de Silva (2005) que se trata de um estudo das relações entre os currículos do Ensino de História e os conteúdos sobre Cinejornal Brasileiro (CJB) produzido pelo DIP (Departamento de Imprensa e Propaganda) no período do Estado Novo.

${ }_{11}$ É preciso dizer que a causa das poucas pesquisas sobre essas fontes também se dá pelas dificuldades para preservação e acesso aos filmes. No Brasil, apesar dos louváveis esforços dos funcionários dos arquivos fílmicos, ainda faltam incentivos governamentais e da iniciativa privada para disponibilização de recursos. Infelizmente, muito do que foi produzido já se perdeu e as séries que hoje são encontradas nas instituições sofrem com a falta de políticas culturais mais sólidas. A divulgação de traba-
} 


\section{Análise de fontes históricas: em foco, o cinejornal Bandeirante da Tela}

Raymond Williams e outros autores ${ }^{12}$ que reconhecem a importância da cultura para o estudo da sociedade rompendo com um antigo economicismo que marcava os anteriores estudos marxistas, alertam para as leituras superficiais que tomam como central uma suposta modelação dos sujeitos postos em contato com os meios. Nessa revisão historiográfica, a cultura é definida pela compreensão de que "os seres humanos não são meros produtos dos meios envolventes, [do mesmo modo que] estes também não são totalmente moldáveis para arbitrária automodelação dos primeiros (EAGLETON, 2005, p. 15)”.

Sob outras perspectivas teóricas, o historiador Michel de Certeau ${ }^{13}$ também se ocupou das questões culturais ao estudar as práticas da leitura e escrita, e recorreu algumas vezes em seus estudos sobre as "artes de fazer com" às proposições da escritora e cineasta francesa Marguerite Duras. A referência serviu para reconhecer as astucias dos leitores (ou espectadores) na ação leitora e interpretação dos textos (ou imagens). “Talvez se leia sempre no escuro... A leitura depende da escuridão da noite. Mesmo que se leia em pleno dia, fora, faz-se noite em redor do livro ${ }^{14}$ ". Por mais que existam forças para conduzir certos modos de interpretação (papel do professor na escola, do locutor e do comentarista no rádio, cinema e televisão), a leitura é algo que se realiza "no escuro" envolta por imprecisões, o que contraria a ideia de modelação/doutrinação dos sujeitos.

lhos de pesquisa que utilizem essa fonte também é fundamental para o reconhecimento da importância desse material para a compreensão de grande parte da história do país.

12 Reunidos em torno da New LeftReview (1960), como Perry Anderson, Christopher Hill, Eric Hobsbawm e Edward Palmer Thompson.

13 Teórico que representa a chamada virada linguística (linguisticturn, semioticchallege) para a historiografia.

14 DURAS, M. Le camion, Paris, Minuit 1977; "Entretien à Michèle Porte", cit. em Sorcières, n. 11, janeiro de 1978, p. 17 apud Certeau (2014, p. 245). 
A historiadora Tania Regina de Luca especialista no estudo sobre periódicos (jornais e revistas) e sobre a utilização dessas fontes nos trabalhos históricos também cita Marguerite Duras para tratar da falsa objetividade que limitou por muito tempo a consideração desses documentos pela historiografia. Em resposta à uma pergunta do jornalista Danton Jobim sobre a necessidade da imparcialidade no trato dos fatos pelos repórteres, Duras teria respondido: “um jornalista é alguém que observa o mundo e o seu funcionamento (...) e não consegue fazer este trabalho sem julgar o que vê. É impossível. Em outras palavras, a informação objetiva é um logro total. Uma impostura15”.

Apesar de focalizar no tratamento dos periódicos, De Luca faz algumas recomendações fundamentais para estruturar a análise de diversas tipologias de fontes. No artigo em questão, a historiadora adverte para a necessidade de consideração da historicidade e materialidade dos documentos: "Historicizar a fonte requer ter em conta, portanto, as condições técnicas de produção vigentes e a averiguação, dentre tudo que se dispunha, do que foi escolhido e por quê" (LUCA, 2014, p. 132).

Figura 1 - Fotografia de jornal "sem título". Fonte: Jornal de Notícias de $1^{\circ}$ de janeiro de 1950. "Notícias de cinema", pág. 6. Hemeroteca da Biblioteca Nacional.

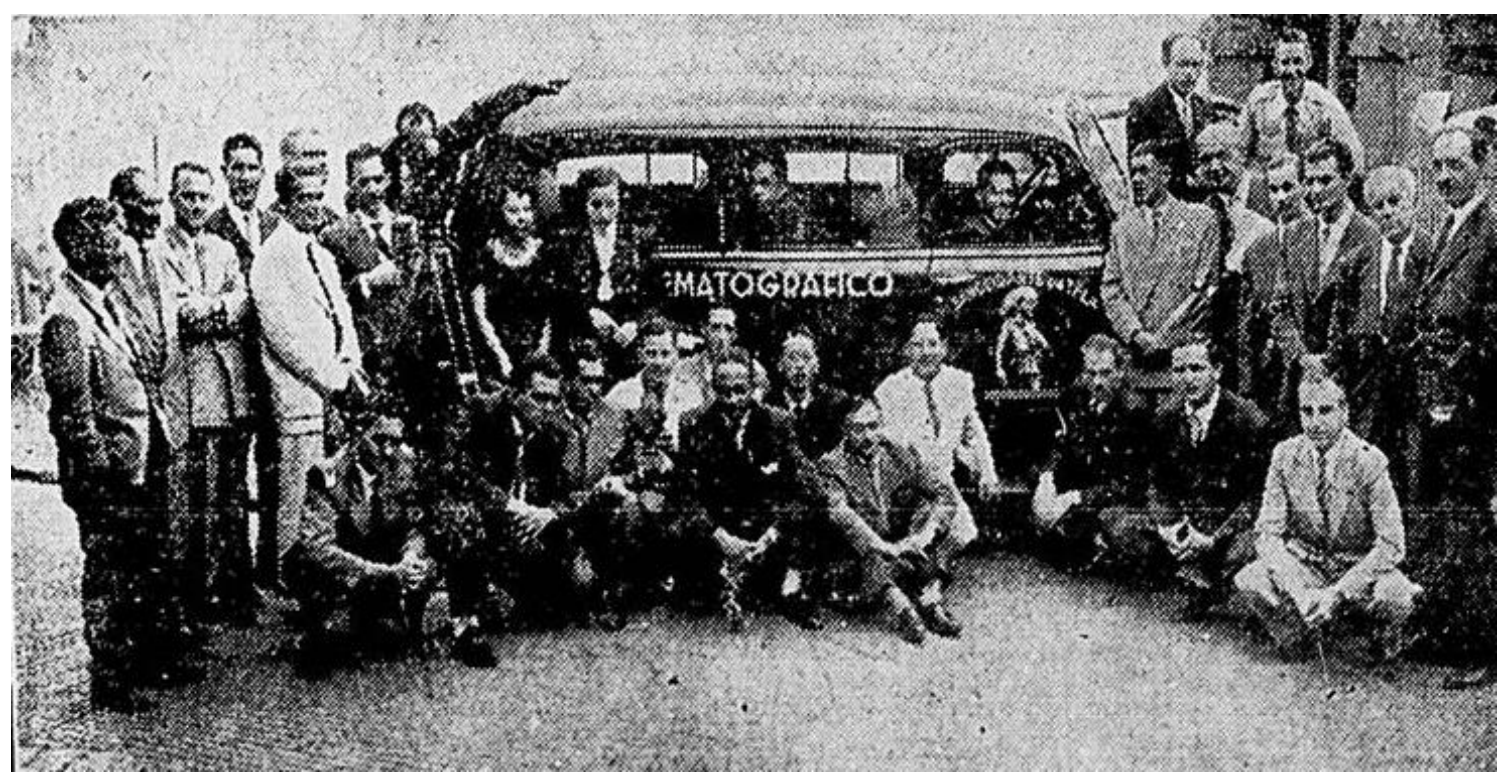

15 JOBIM, D. Espírito do jornalismo. $2^{\text {a }}$ ed. São Paulo: EDUSP, 2003 apud LUCA (2014, p. 139). 
Na fotografia da página anterior, retirada de uma edição do Jornal de Notícias do ano de 1950, podemos ver a equipe da Divulgação Cinematográfica Bandeirante, a empresa que produzia o Bandeirante da Tela. Esta imagem indica que a realização, distribuição e divulgação desse jornal cinematográfico envolviam a participação de muitas pessoas como câmeras, narradores, empresários, diretores, jornalistas e etc.

A legenda da foto no jornal informa a ocasião em que foi tirada, ou seja, na comemoração do $100^{\circ}$ filme realizado pela Divulgação Cinematográfica Bandeirante. No texto há destaque para a presença de alguns nomes que compõe o grupo fotografado e omissão de outros, como por exemplo, as duas mulheres localizadas entre ao letreiro no carro ("cinematográfico") e da câmera sobre o tripé (canto esquerdo):

A equipe da Divulgação Cinematográfica Bandeirante, realizadora dos jornais diários que mantem o Brasil informado do que se passa em São Paulo, promoveu no dia 30 último e por iniciativa de seu diretor, Benedito Sartini, a festa de seu $100^{\circ}$ filme desde a fundação daquela produtora. Vemos no clichê, seus principais diretores, Benedito Sartini e Luís del Picchia, assim como nosso colega Hermantino Coelho, diretor da distribuição, representantes de circuitos exibidores, da imprensa e amigos, poucos momentos antes do almoço no Gigetto ${ }^{16}$.

Tania Regina de Luca também nos alerta sobre a necessidade de interrogarmos sobre o lugar social ocupado pela fonte. No caso do cinejornal Bandeirante da Tela, a reportagem retirada do Jornal de Notícias já nos dá algumas informações: a apresentação - "jornais diários que mantém o Brasil informado" - e a exposição dos nomes - na qual foram colocados somente os nomes dos diretores por serem pessoas mais próximas do mundo da imprensa. É importante prestar atenção nos indícios postos para além dos conteúdos dos cinejornais, esse tipo de documentação complementar dá subsídios para um estudo mais completo do objeto de pesquisa. Desse modo, justifica-se a necessidade do "pesquisador recorrer a outras fontes de informação para dar conta do processo que envol-

16 Jornal de Notícias de $1^{\circ}$ de janeiro de 1950. "Notícias de cinema” pág. 6. Hemeroteca da Biblioteca Nacional. 
veu a organização, o lançamento e a manutenção [neste caso, não] do periódico [mas do cinejornal]" (LUCA, 2014, p. 132-142).

Ainda sobre a fotografia anterior, na porta do carro vemos a mesma imagem da cartela de apresentação nas edições do Bandeirante da Tela, a figura de um bandeirante (abaixo):

Figura 2 - Na imagem à esquerda, um recorte da fotografia do jornal. Fonte: Jornal de Notícias de $1^{\circ}$ de janeiro de 1950. "Notícias de cinema" pág. 6. Hemeroteca da Biblioteca Nacional. Figura 3 - Na imagem à direta, um fotograma com carta de apresentação do cinejornal. Fonte: Bandeirante da tela - edição especial. Cinejornal, sonoro, não ficção. 35mm, BP, 10min54seg, 300m, 24q. Acervo da Cinemateca Brasileira.
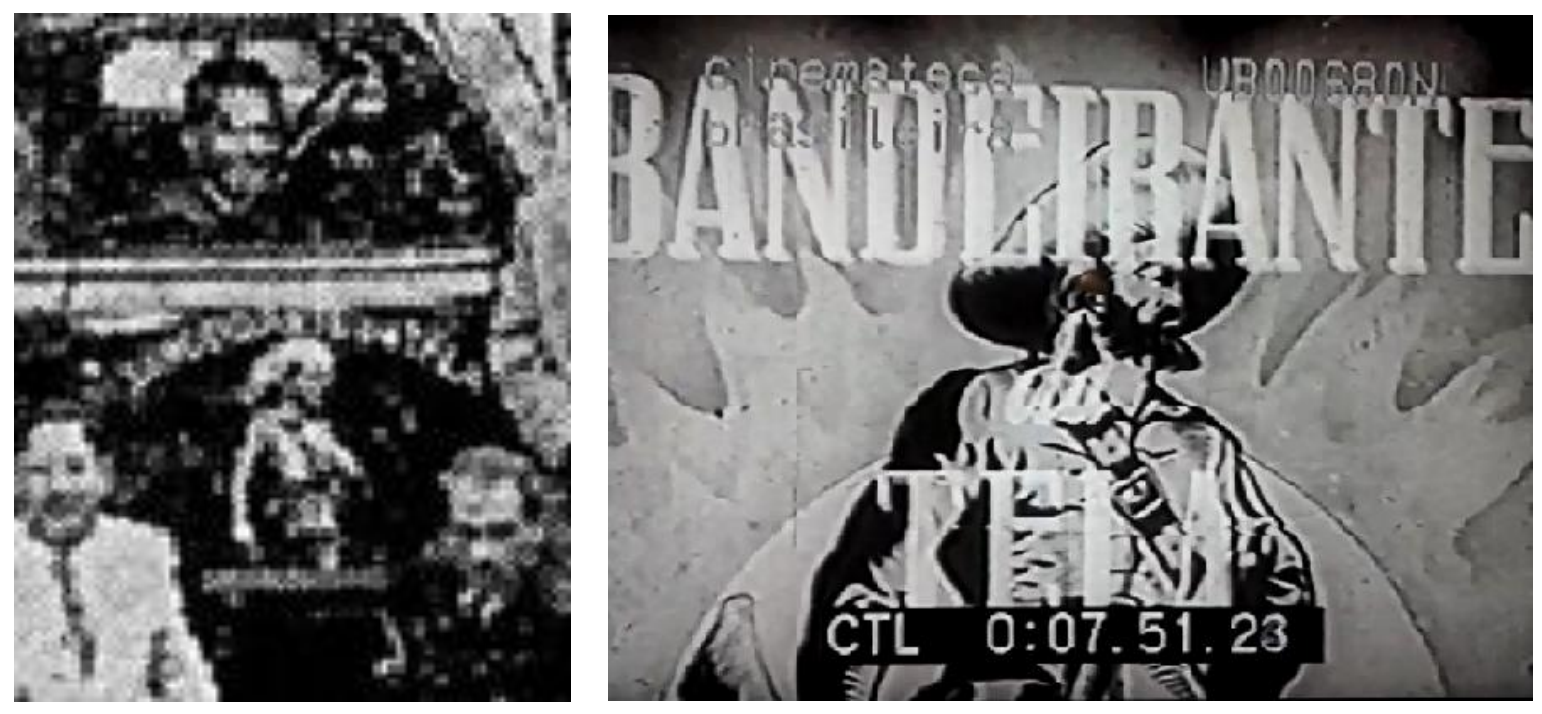

Marcos Napolitano (2014), também em um texto sobre o tratamento inicial das fontes históricas, faz apontamentos direcionados aos documentos audiovisuais (música, cinema e televisão). Selecionando o que diz respeito ao cinema, destaco duas demandas essenciais para o trabalho com os filmes: a problematização do "efeito de realidade" e o tratamento do conteúdo narrativo.

Na primeira, o historiador lembra o trabalho de Roland Barthes, que descreve esse efeito na fotografia, pela produção de uma "adesão imediata entre o referente (a 'realidade' fotografada) à representação (o registro fotográfico em si)". No caso dos filmes documentários e dos diversos tipos de jornalismo (no rádio, no cinema e na TV) esse efeito parece se potencializar. Mesmo que os assuntos chegassem mais atrasados no 
cinema (do que no jornal e no rádio), na época dos cinejornais (quando não havia televisão) as imagens em movimento tinham um poder de conferência sobre o que aconteceu. Era possível encontrar alguém que falasse: "Eu já sabia que aquilo tinha acontecido. Mas lá no cinema, eu realmente vi como tudo aconteceu". Esse efeito de proximidade com os acontecimentos transformou os cinejornais em poderosos meios de propaganda política e de constituição de um conjunto ideal de comportamentos sociais servindo ao processo de desenvolvimento de um país urbanoindustrial.

A segunda demanda de análise se desdobra em "linguagem técnicoestética", "códigos internos de funcionamento" e as "formas de representação da realidade histórico ou social”. Para além, dos fatores externos ao filme, é preciso que fiquemos atentos também a construção narrativa através da análise das imagens. "O enquadramento de uma cena, a edição de um filme, a cor/textura empregada na captação da imagem, são fundamentais para que o filme ganhe o sentido cultural, estético, ideológico e, consequentemente, sócio-histórico" (NAPOLITANO, 2014, p. 267).

\section{4: cultura política no cinema}

Em 9 de julho de 1954 iniciaram as comemorações promovidas pela Associação das Emissoras de São Paulo no IV Centenário da cidade. Foram três dias de festejos que ocorreram em diversos lugares da capital: iniciando no Pátio do Colégio, seguindo para a Praça da Sé, Faculdade de Direito, Anhangabaú, Avenida Nove de Julho, Estádio do Pacaembu, e terminando na noite de 11 de julho, no Alto de Pinheiros. Desfiles, missa, hasteamento de bandeiras e outras atividades cívicas e religiosas foram realizadas com o intuito de celebrar o aniversário da cidade "que mais cresce no mundo" 17.

${ }_{17}$ Em aspas, palavras transcritas da fala do narrador. 
A edição especial do Bandeirante da Tela é um resumo desses três dias de festividade. Para essa produção fílmica foi dado o título: "9 de julho em São Paulo no IV Centenário - Epopéia da Brasilidade”.

Figura 4 - Fotograma com o título da edição do cinejornal: "9 de julho em

São Paulo no IV Centenário: Epopeia da Brasilidade”. Fonte: Bandeirante da tela - edição especial. Cinejornal, sonoro, não ficção. $35 \mathrm{~mm}, \mathrm{BP}$, 10min54seg, 300m, 24q. Acervo da Cinemateca Brasileira.

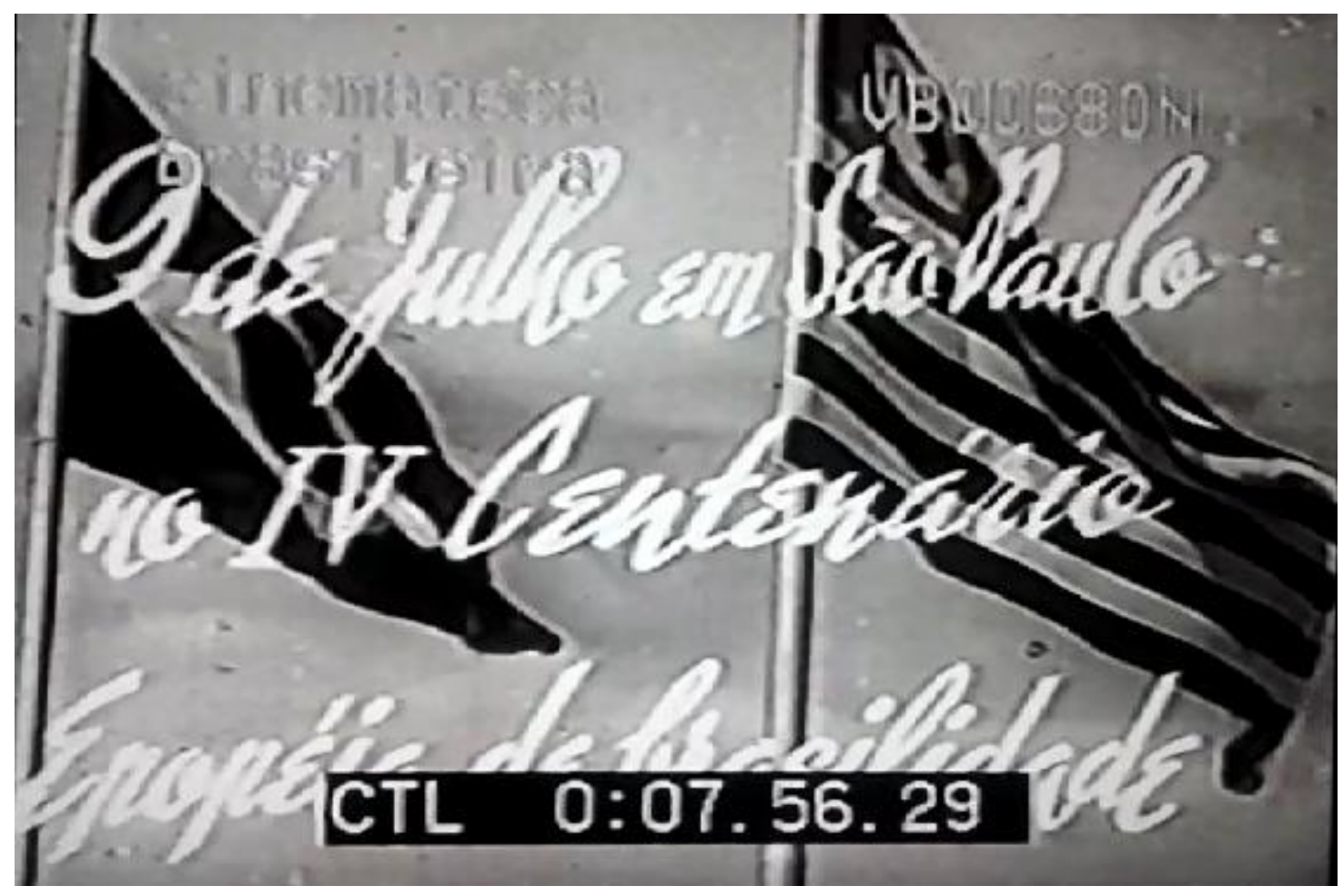

O filme começa com uma tomada em câmera baixa (contraplongée) dos prédios mais altos do centro da cidade, com destaque para as sedes do Banco do Brasil e do Banco do Estado de São Paulo (Banespa). Em seguida, aparecem as pessoas reunidas no Pátio do Colégio, em frente ao prédio da Secretaria da Agricultura, "local onde Anchieta a mandato de seu superior Nóbrega ergueu a casa de torrão e palha aduariana a 14 passos de comprido e 12 de largo. De onde Manoel de Paiva rezou missa ${ }^{18}$ ". Misturam-se o crescimento vertical da cidade, os símbolos do mercado financeiro do país e de São Paulo mostrando como um

18 Idem. 
estava atrelado ao outro, a importância da produção agrícola e da comercialização dos produtos e a história da fundação da cidade que representava o progresso econômico do país. Delineia-se assim a denominada "Epopéia da brasilidade".

O Prédio Banespa começou a ser construído em 1939 e foi inaugurado em $1947^{19}$. Essas duas fases foram cumpridas nas gestões de Adhemar Pereira de Barros (a primeira, como interventor federal, e a segunda, como governador). Essa construção aparece logo na primeira imagem registrada pela equipe da Divulgação Cinematográfica Bandeirante de propriedade da família do mesmo político paulista ${ }^{20}$.

Jânio Quadros assumiu a Prefeitura de São Paulo no início do ano do IV Centenário, e já especulavam sobre sua candidatura para o governo do Estado para o ano seguinte. Sua carreira em ascensão passava a ameaçar as pretensões de Adhemar de Barros e de seus correligionários no Partido Social Progressistas (PSP), com exemplo do então governador Lucas Nogueira Garcez. Além disso, com a entrada do novo prefeito, este passou a participar na organização final dos eventos de 1954 que antes tinham sido majoritariamente coordenados pelos políticos do PSP, gerando assim, uma disputa de interesses.

$\mathrm{Na}$ edição especial, o narrador Marino $\mathrm{Neto}^{21}$ enfatiza no início do filme e reitera no final que em julho os festejos haviam sido diferentes dos outros ocorridos no mesmo ano devido ao "grande alcance popular" e "o povo esquecido em todas as comemorações anteriores sentiu-se feliz em poder participar dos festejos da maior cidade"22. Realizado em prol da divulgação dos eventos promovidos pelas emissoras, o cinejornal serviu para reforçar o tom populista das campanhas e propagandas de Adhemar

\footnotetext{
19 Atualmente, um dos pontos turísticos mais conhecidos da cidade, visto como um representante da sua paisagem histórica.

20 Rodrigo Archangelo confirmou essa informação em seu trabalho de mestrado cujo objeto de pesquisa é o Bandeirante da Tela tratado como um veículo de promoção da política populista de Adhemar de Barros. Na dissertação (2007), o historiador também afirma que Adhemar aparece em pelo menos um terço das edições do cinejornal. Adhemar também era proprietário do jornal O Dia e da Rádio Bandeirantes ${ }^{20}$, uma das emissoras que patrocinou o evento de julho de 1954.

${ }^{21}$ Marino Neto era também locutor de rádio e uma voz bastante conhecida na época.

22 Em aspas, palavras transcritas da fala do narrador.
} 
de Barros. Em outras edições, nas quais o político aparece como figura central, ele está sempre cercado por um grande número de pessoas e procura se mostrar disposto em estar próximo do povo, com muitos acenos e apertos de mão. É por isso que ao analisar as imagens dos festejos de julho, o historiador Rodrigo Archangelo (2015, p. 166) considera:

\begin{abstract}
A data que melhor traduz a "epopéia paulistana", justamente o dia da deflagração da Revolução de 1932, foi oportuna naquele ano para salientar a força retórica do bandeirantismo ostentado por Adhemar de Barros. Não deixando também passar a oportunidade de capitalizar politicamente o IV Centenário. A tônica do registro mostrado no BT [Bandeirante da Tela] não podia ser outra: as autoridades competentes fracassaram em organizar as comemorações do IV Centenário, por isso coube à iniciativa apoiada por Adhemar de Barros não deixar passá-lo despercebido.
\end{abstract}

No dia 9 de julho, a cidade que passava de "burgo colonial" para "metrópole pujante", tem sua história representada por uma "anciã de 120 anos" e o seu futuro por um "menino de 5 anos" que juntos hasteiam as bandeiras do Estado de São Paulo e do Brasil ao som da Banda dos Fuzileiros Navais. Segue para a Praça da Sé uma solene missa com a presença do arcebispo auxiliar de São Paulo, onde se apresentavam vestidas de anjo, "centenas de meninas" cujo propósito era o de "enfeitar de graça e pureza”o evento na nova Catedral, com outras jovens "centenas de vozes" que compunham um coral23. Entre as pessoas ali presentes passa uma imagem da Nossa Senhora do Brasil. A santa cuja aparição aconteceu no interior do Estado 24 e escolhida como padroeira do país, tratavase de outro símbolo da brasilidade advinda de São Paulo.

Da missa na Praça da Sé, segue uma tomada da Faculdade de Direito de São Paulo, Marino Neto em voz mais alta destaca a frase grafada na fachada do prédio "Non Ducor Duco, o emblema da cidade, não sou conduzido, conduzo" e as personalidades que estudaram na instituição: "a heróica Faculdade de Direito de Castro Alves, Fagundes Varella, Alvares Penteado e do MMDC", nomes conhecidos pela história oficial do Estado

23 Idem.

24 Na cidade que recebeu o nome de Aparecida do Norte. 
e do país ${ }^{25}$. Em seguida, duas imagens feitas do alto da cidade (provavelmente de cima de prédios), recurso de filmagem para exaltar "o grande comparecimento popular". Na continuação, acontecem os desfiles de inúmeras bandas, e à noite a afamada chuva de prata ${ }^{26}$ :

\begin{abstract}
Ainda no dia 9 de julho um espetáculo maravilhoso e inédito no Brasil, chuva de prata. Pela primeira vez foi vista na Inglaterra na coroação quando uma tonelada de estrelas prateadas caiu das alturas. Nos céus de São Paulo 12 toneladas de estrelas prateadas se derramaram sobre a cidade. Decepcionados com as comemorações anteriores, organizadas pelas comissões do governo e da Prefeitura que resultaram em completo fracasso, prazer invisível envolviam os paulistas ao verem que não passaram despercebidos no IV Centenário e o 9 de julho. O povo nas ruas assistia extasiado 27.
\end{abstract}

A coroação da Rainha Elizabeth II aconteceu no ano anterior, em junho de $1953^{28}$, e se na Inglaterra colocaram uma tonelada de papéis picados, em São Paulo jogaram 12 vezes mais. A divulgação desse dado servia para assinalar a potencialidade da cidade de São Paulo para ser reconhecida internacionalmente. Além disso, mais uma vez marcou-se a diferença entre as comemorações anteriores, que não contaram com tamanha grandiosidade e participação entusiasmada do povo. No entanto, é um tanto curioso saber pela programação dos eventos de janeiro publicada na revista $\mathrm{O}$ Cruzeiro ${ }^{29}$ que no dia 25 de janeiro também ocorreu uma "chuva de prata", na região do Anhangabaú, talvez não com a mesma quantidade de papéis e/ou com menos pessoas assistindo.

\footnotetext{
25 A sigla é composta das iniciais de Martins, Miragaia, Dráuzio e Camargo, estudantes da Faculdade de Direito que morreram nos conflitos armados de 1932.

26 Em aspas, palavras transcritas da fala do narrador.

27 Idem

${ }^{28}$ A coroação foi registrada em um documentário em tecnicolor (colorido) com o título de "A Queen is crowned" (1953). Há informações sobre esse título na base de dados online IMDb (Internet Movie Database). Disponível em: http://www.imdb.com/title/ tto046222. Acesso em: 21 dez. 2016.

29 Sobre os eventos realizados para o IV centenário de São Paulo, e principalmente essa programação de janeiro, vide Lofego (2004, p. 65-66).
} 
No dia 10 de julho, a festa continuou no Estádio do Pacaembu3o com a apresentação de números de circo e de ginástica. E por fim, no dia seguinte, houve uma queima de fogos no Alto de Pinheiros, "junto à estrada das boiadas". O caminho por onde ocorreram os eventos ratificava a expansão da cidade para região oeste e a sua ligação para o Centro através da Avenida Nove de Julho. A passagem por essa Avenida também tinha um propósito que era "marcar o trajeto do antigo Rio Anhangabaú, em demanda do Tamanduateí, para formarem o Tietê, lendário e histórico"31. Na cachoeira que se formou pelos fogos de artifício surge o emblema da Associação das Emissoras de São Paulo, apontando mais uma vez quem foram os responsáveis pela organização dos eventos de julho. Esse fato serve para constatarmos a utilização dos meios de comunicação na construção das narrativas sobre a cidade e evidenciarmos que a cultura política era algo pensado e articulado no contexto de expansão desses meios.

\section{Educação e ensino na narrativa do IV Centenário}

O escopo deste último item é abordar o modo como os temas sobre a escola e a educação completavam o processo de idealização da ascensão de uma metrópole. A partir disso, são levantados alguns símbolos que aparecem nas imagens registradas no cinejornal sobre o IV Centenário de São Paulo. Ideias e símbolos relativos à educação e ao ensino estão nas imagens e receberam destaque na voz do narrador32.

30 Estádio Municipal Paulo Machado de Carvalho, inaugurado em 1940, pelo então interventor federal Adhemar de Barros e prefeito Prestes Maia, este nomeado pelo primeiro em 1938.

${ }^{31} \mathrm{Em}$ aspas, palavras transcritas da fala do narrador.

$3^{2}$ As edições correntes do cinejornal Bandeirante da Tela eram divididas por sessões com diferentes temas de notícias, dentre as quais "Conheça sua terra", "Futebol", "Notícias Esportivas", "Artes e Artistas", "Notícias diversas", "Crônica Social”, "Aviação”, "Cinema e Teatro", "Visitantes Ilustres", "Vida Militar”, "Saúde Pública”, "Assistência Social” e também "Educação e Ensino". 
Em 9 de julho, um grupo de meninas em apresentação de canto em coral, a presença das bandeirantes, as imagens da Faculdade de Direito e o desfile das bandas colegiais (no qual aparece na imagem uma faixa do Liceu Coração de Jesus) e dos alunos da Miami Jackson High School. Por fim, na parada noturna, uma alegoria dos alunos da Escola Caetano de Campos e a passagem dos atletas de grêmios esportivos e clubes da cidade.

Em 10 de julho, no Estádio do Pacaembu, trapezistas, palhaços, um gigante de perna de pau, motocicletas no globo da morte e a apresentação realizada pelos alunos da Escola de Educação Física. Salienta-se nas imagens e na narração sobre esse dia uma grande presença de crianças assistindo o evento.

O canto coletivo era um dos elementos constitutivos das festas cívicas no Brasil, principalmente depois da Era Vargas, através de projetos políticos e da atuação de Heitor Villa Lobos responsável pela divulgação do chamado Canto Orfeônico, que passou a fazer parte dos programas escolares nos anos 1940. O músico foi também um dos críticos nas propostas de organização do IV Centenário, escrevendo à Comissão sobre a falta de elementos da cultura nacional na programação dos festejos33.

Havia uma série de grupos formados no Brasil com intenções educativas e cívicas, e o escotismo e o bandeirantismo eram uns dos mais evidenciados, como demonstra o cinejornal. De acordo com a pesquisadora Rosa Fátima de Souza (2000), em artigo sobre a militarização da infância no início do século XX, o escotismo é um exemplo das iniciativas de cunho nacionalista, sendo motivo de debate entre os educadores. Eles discutiam sobre a necessidade da entrada do escotismo nos espaços escolares. Já em 1921, o decreto 3.355/21 de regulamentação da Reforma da Instrução Pública (27/05/1921) afirmava que "todos os alunos matriculados nas escolas públicas seriam considerados aspirantes a escoteiros" e "os professores de ginástica das escolas normais e das escolas complementares seriam os instrutores do escotismo”. Mesmo com a legislação, educadores e políticos, a exemplo de Lourenço Filho, reiteravam a práti-

33 Vide trecho da carta de Villa Lobos à Comissão com essas críticas in Lofego (2004, p. 48). 
ca do escotismo na escola para fosse além do somente "escotismo 'de parada”" limitado às apresentações nas festas cívicas 34 . Vimos pelo cinejornal, que a presença dos jovens fardados de escoteiros continuava em eventos cívicos nos anos 1950, sendo que nesse período o movimento ganhou um estatuto único (UEB - União dos Escoteiros do Brasil) para todas as unidades do país.

Figura 5 - Fotograma do cinejornal com imagem das jovens do coral.

Fonte: Bandeirante da tela - edição especial. Cinejornal, sonoro, não ficção.

35mm, BP, 10min54seg, 300m, 24q. Acervo da Cinemateca Brasileira.

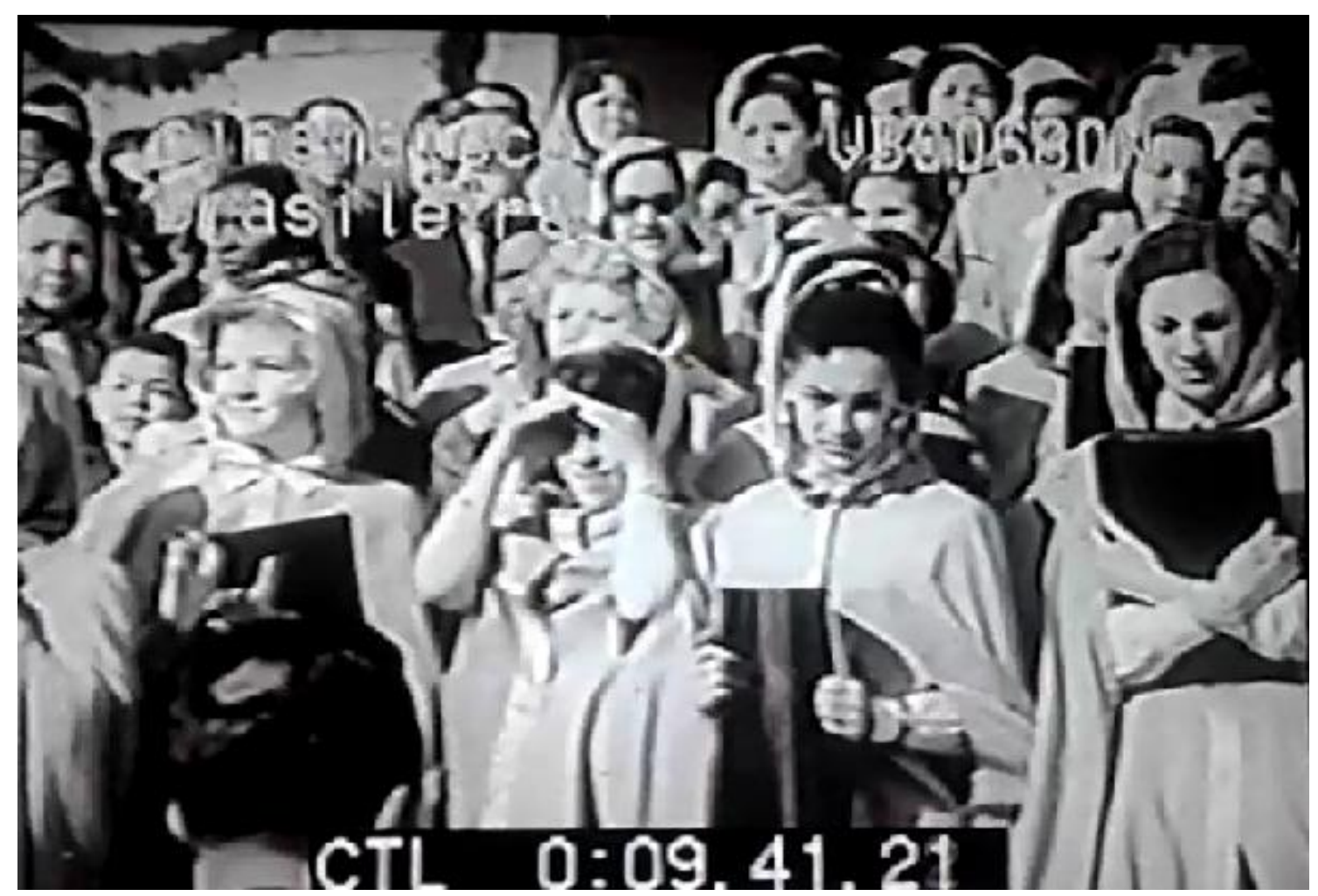

Na maioria dos casos, os grupos dos escoteiros de São Paulo recebiam o nome de algum bandeirante, e as jovens que se reuniam nos grupos femininos 35 eram todas chamadas de bandeirantes. Esses grupos recorriam ao mito dos personagens considerados como desbravadores do terri-

34 Uma das frases de resposta de Lourenço Filho ao inquérito sobre a educação organizado por Fernando de Azevedo em 1926 (LOURENÇO FILHO apud HEROLD JR, 2011, p. 130).

35 Inspirado no movimento das Girl Guides da Inglaterra. 


\section{Revista de História e}

Historiografia da Educação

tório e marcantes na história oficial do Estado de São Paulo. Essa mesma simbologia aparece no nome do cinejornal e na imagem da carta de apresentação que se assemelha às estátuas dos bandeirantes abrigadas no Museu Paulista36. Podemos lembrar também do nome da Rádio Bandeirantes e do Monumento às Bandeiras em frente ao Parque do Ibirapuera como dois outros marcos da importância dada aos bandeirantes como representantes oficiais da História do Brasil a partir de São Paulo.

Figura 6 - Fotograma do cinejornal com imagem do desfile (no canto esquerdo, parte da faixa do Liceu Coração de Jesus). Fonte: Bandeirante da tela - edição especial. Cinejornal, sonoro, não ficção. $35 \mathrm{~mm}$, BP, 10min54seg, 300m, 24q. Acervo da Cinemateca Brasileira.

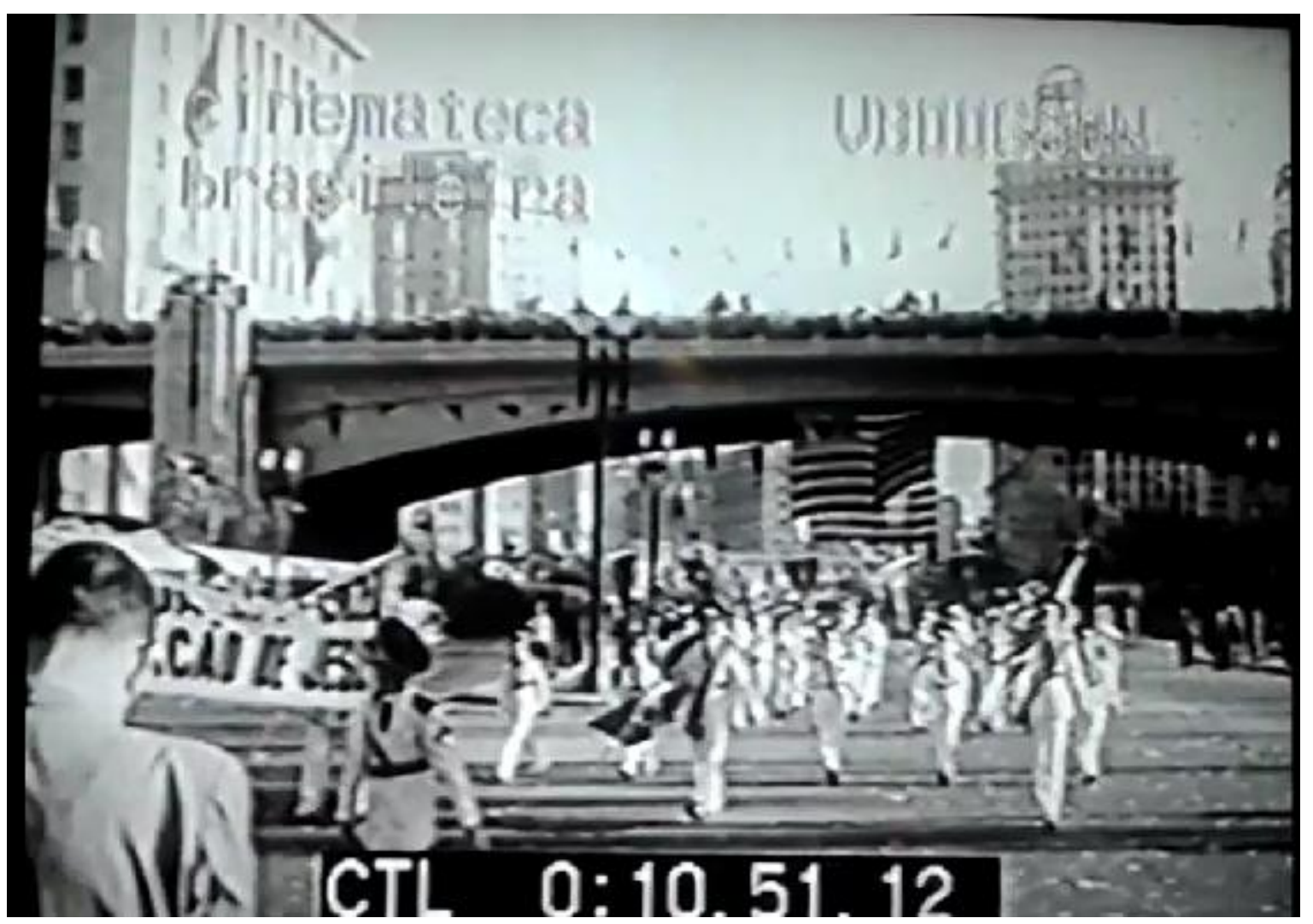

Sobre as instituições de ensino que aparecem nas imagens, o ensino superior é simbolizado pela Faculdade de Direito e a Escola de Educação Física do Estado de São Paulo que possuía o curso superior de Educação

${ }^{36}$ Do artista Luigi Brizzolara (1920). 
Física, mas também outros, de caráter técnico37. O ensino básico é marcado pela presença dos alunos das bandas colegiais e dos desfiles, com destaque para uma instituição confessional, o Liceu Coração de Jesus (Salesianos) e para a Escola Caetano de Campos, arauto da educação republicana desde o final do século XIX e referência de ensino público. Também se destaca a vinda promovida pela Rádio Bandeirantes dos alunos de uma escola dos Estados Unidos, da qual podemos retirar que o ensino norte-americano era visto como um modelo de excelência a ser seguido. Nesse período, as relações entre Brasil e Estados Unidos estavam cada vez mais se consolidando, principalmente a partir empréstimos de capital e na abertura para a entrada de multinacionais no território brasileiro, o que exercia influência nas mudanças ocorridas na cidade e no Estado de São Paulo.

Por último, destaca-se por alguns motivos a combinação de atividades circenses e de ginástica ocorridas no Estádio do Pacaembu. Primeiro, o significativo valor dado a presença das crianças. Aliás, o cuidado com a infância, os Parques Infantis, e o assistencialismo nas datas comemorativas (Natal e Dia das Crianças) de Adhemar de Barros (e de sua esposa, Leonor Mendes de Barros) são exaltadas nas edições do Bandeirante da Tela. Segundo, justifica-se a importância da realização de estudos que deem conta da análise das relações entre essas modalidades (circo e ginástica), e também, da influência e presença das atividades circenses nos programas escolares.

As festas se constituem como instrumento de legitimação de uma série de símbolos para a composição de imaginários coletivos sobre a cidade. Corroborando com essas prerrogativas, os meios de comunicação reelaboram essas representações fazendo uma seleção e divulgando tudo que deveria ser mostrado, construindo assim uma narrativa alternativa dos acontecimentos. Possivelmente, as emissoras resolveram saudar os

37 Curso de Normalista Especializada em Educação Física, Curso de Técnica Desportiva, Curso de Medicina Especializada em Educação Física e Curso de Massagem Especializada em Educação Física. Informações retiradas do regimento aprovado por Adhemar de Barros no decreto 19.819-F, em 11 de outubro de 1950. Disponível em: http://www.al.sp.gov.br/repositorio/legislacao/decreto/1950/decreto-19819F11.10.1950.html. Acesso em 21.12.2016. 


\section{Revista de História e}

\section{Historiografia da Educação}

seus expectadores e ouvintes e demonstrar a todos (incluindo então, políticos e empresários) suas capacidades de intermediação e proximidade com o povo. Para passar nos cinemas, interessava mostrar os aspectos mais pujantes na promoção de uma grande festa que servia de alegoria para uma cidade a ser celebrada tanto pelo seu passado quanto por suas possibilidades de futuro. Nesse sentido, ficaram de fora outros temas que poderiam ser abordados como as escolas que não foram construídas em tempo para os festejos ${ }^{3}$, o elevado número de crianças em idade escolar que ainda não tinham acesso ao ensino e as distintas formações dirigidas aos mais ricos e aos mais pobres.

Figura 7 - Fotograma do cinejornal com imagem de crianças na grade do Estádio do Pacaembu assistindo as apresentações de circo e de ginástica. Fonte: Bandeirante da tela - edição especial. Cinejornal, sonoro, não ficção.

35mm, BP, 10min54seg, 300m, 24q. Acervo da Cinemateca Brasileira.

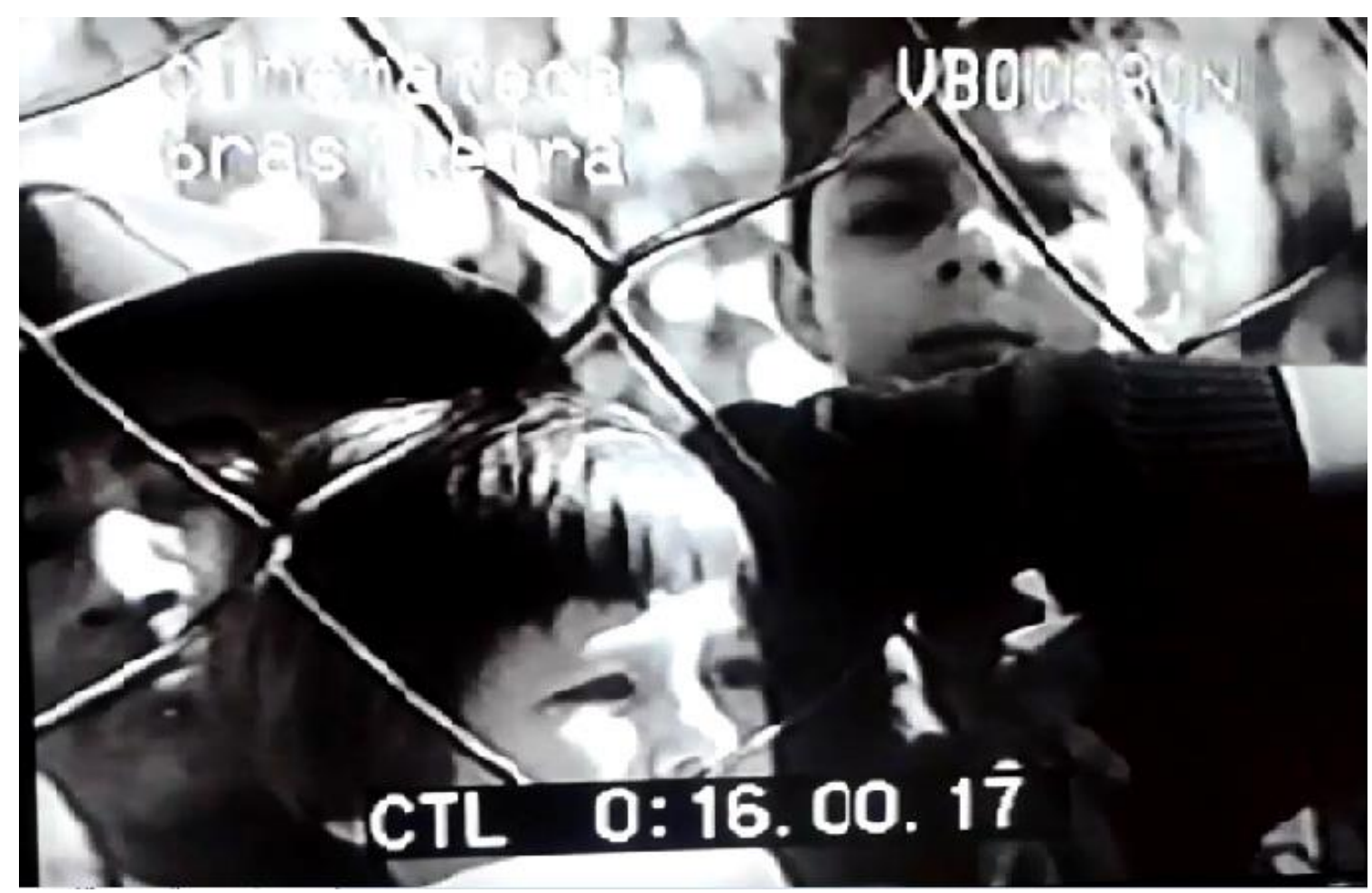

38 Tanto isso ocorreu que de acordo com Sposito (2001, p. 110), a Secretaria da Educação do Estado adotou como medida emergencial, no ano seguinte, a abertura de novas classes e o funcionamento de quatro períodos nos grupos escolares já existentes. Além disso, um novo Convênio Escolar foi assinado no final de 1954 com o intuito de continuar na construção de instituição e de buscar ainda cumprir a meta de vencer os déficits de falta de vagas. 
Para concluir, vale dizer que cabe a nós, pesquisadores, analisarmos com atenção as narrativas interrogando os fatores internos e externos das imagens e reunindo o maior número possível de documentos. A análise do cinejornal empreendida neste artigo certamente não pode ser vista como definitiva, a intenção de realizar o levantamento foi apenas um primeiro passo de muitos que ainda podem ser dados no estudo de discursos e simbologias elaborados sobre São Paulo. Este trabalho cumpre a tarefa de mostrar que é possível pensarmos na educação como um dos elementos de constituição das múltiplas narrativas sobre a cidade tanto na celebração dos seus 400 como de outros anos.

\section{Referências}

ABREU, I. R. N. Convênio escolar: utopia construída. Dissertação de mestrado (Arquitetura e Urbanismo). Universidade de São Paulo, São Paulo, 2007.

ARCHANGELO, R. Um bandeirante nas telas de São Paulo: o discurso Adhemarista em cinejornais (1947-1956). Dissertação de mestrado (História Social). Universidade de São Paulo, São Paulo, 2007.

. Um bandeirante nas telas de São Paulo: o discurso Adhemarista em cinejornais (1947-1956). São Paulo: Alameda, 2015.

EAGLETON, T. A ideia de cultura. São Paulo: Editora UNESP, 2005.

CERTEAU, M. A invenção do cotidiano: 1 . Artes de fazer. $22^{\mathrm{a}}$ ed. Petrópolis: Vozes, 2014.

HEROLD JR., C. A educação corporal no paraná através do movimento escoteiro em Guarapuava (1927-1936). Educação em Revista, v. 27, n. 2, p. 123-150, 2011.

LOFEGO, S. L. IV Centenário de São Paulo: uma cidade entre o passado e o futuro. São Paulo: Annablume, 2004.

LUCA, T. R. História dos, nos e por meio dos periódicos. In: PINSKY, C. B. (org). Fontes históricas. $3^{\text {a }}$ ed. São Paulo: Contexto, 2014, p. 111-154. 
MATOS, M. I. S. A cidade que mais cresce no mundo: São Paulo território de Adoniram Barbosa. São Paulo em Perspectiva, v .15, n. 3, p. 50-57, 2001.

MEDEIROS, A. Cinejornalismo brasileiro uma visão através das lentes da Carriço Film. Juiz de Fora Edições Funalfa, 2008.

NAPOLITANO, M. A História depois do papel. In: PINSKY, C. B. (org). Fontes históricas. $3^{\text {a }}$ ed. São Paulo: Contexto, 2014, p. 235-290.

SANTORO, P. A relação do espaço urbano com a sala de cinema em São Paulo: do provinciano ao cosmopolita. Dissertação de mestrado (Arquitetura e Urbanismo), Universidade de São Paulo, São Paulo, 2004.

SANTOS, A. C. N. A Estética Estadonovista: um estudo acerca das principais comemorações oficiais sob o prisma do Cine-Jornal Brasileiro. Dissertação de mestrado (História), Universidade Estadual de Campinas, Campinas, 2004.

SILVA, A. C. M. Ensino de história, cinema, imprensa e poder na Era Vargas (1930-1945). Dissertação de mestrado (Educação), Universidade de São Paulo, São Paulo, 2005.

SIMIS, A. Estado e cinema no Brasil. São Paulo: Annablume, 1996.

SPOSITO, M. P. O povo vai à escola: a luta popular pela expansão do ensino púbico em São Paulo. São Paulo: Edições Loyola, 1992.

SOUZA, J. I. M. Trabalhando como cinejornais: relato de uma experiência. História: Questões \& Debates, n. 38, p. 43-62, 2003.

SOUZA, R. F. A militarização da infância: Expressões do nacionalismo na cultura brasileira. Cadernos Cedes, ano XX, n. 104, p. 104-121, 2000.

TOMAIM, C. "Janela da alma": Cinejornal e Estado Novo - fragmentos de um discurso totalitário. São Paulo: Annablume/FAPESP, 2006.

. Entre insultos e nacionalismos: o documentário na crítica cinematográfica brasileira (1920-1950). Projeto História, n. 43. P. 195-226, 2011.

WILLIAMS, R. Palavras-chave: um vocabulário de cultura e sociedade. Boitempo, 2007. 